\title{
The language scripts of pre-school children and of the language intervention volunteer: Mismatched discourses?
}

\author{
Frenette Southwood and Eden D'Oliveira \\ Department of General Linguistics, Stellenbosch University, South Africa \\ E-mail: fs@sun.ac.za
}

\begin{abstract}
Children with low socioeconomic status (SES) often enter school with poor language skills (Raizada, Richards, Meltzoff and Kuhl 2008), and fall further behind their middle-class peers with every passing grade (cf. Cunningham and Stanovich 1997). This frequently results in academic failure and premature school exit (Astone and McLanahan 1991; Catts, Fey, Tomblin and Zhang 2002), which perpetuates the cycle of limited life chances. Early intervention is often recommended for these children in an attempt to render them less vulnerable to such academic failure. This study considers the practice of such early language intervention. It reflects on the lessons learnt from a language stimulation programme implemented by a dedicated volunteer in a childcare centre in an isolated farming valley in the Stellenbosch area. Some children attending this centre received deliberate language stimulation in a small-group setting on a weekly basis for 18 weeks spread over 6 months. Formal pre- and post-intervention language test scores indicated limited gains for this group, with no statistically significant differences (i) between the group's pre- and post-stimulation scores or (ii) between those children who received the language stimulation and those who did not. Although other, difficult-to-measure gains could be observed (such as increased confidence in interaction with the volunteer, better class participation, and increased positive risk-taking), the stimulation programme failed to yield statistically significant improvement in language skills. The question arises as to why this is the case: Would the children have shown significant improvement over a longer period of time? Is the formal language test inappropriate for use with these children? Or should the practice of a middle-class volunteer entering these children's low-SES world be reconsidered? The paper considers the apparent failure of early language intervention to achieve its goal, namely to give linguistically under-prepared children a fair chance at participating in classroom discourse.
\end{abstract}

Keywords: language stimulation programme, low SES, volunteer, DELV, REALt

\section{Introduction}

Language competence and proficiency are key determinants of literacy development and general educational success (Scarborough 2001; Snow, Burns and Griffin 1998; VernonFeagans 1996; Vernon-Feagans, Scheffner Hammer, Miccio and Manlove 2002). More than 
merely the ability to take part in everyday conversations is at issue here: Language competence and proficiency also pertain specifically to language for academic purposes (Van Rooyen and Jordaan 2009:271).

Westby (1994:341) states that "in the pre-school years, children learn to talk but as they move into school they talk to learn". Children from homes with low socioeconomic status (SES) often enter school with language skills that are poor compared to those of their middle-class peers (cf. Roy, Chiat and Dodd 2014). They tend to have smaller vocabularies than their middle-class peers (Hart and Risley 1995; Raizada et al. 2008). Other language skills of children from lowSES households are also generally less well developed than those of children from more affluent homes, because the latter group receives input that is qualitatively and quantitatively better, a point to which we return later in the paper.

Not only do children from low-SES backgrounds enter school with poorer language skills than their middle-class peers, they also fall further behind these peers with every passing grade (cf. Cunningham and Stanovich 1997). The lower levels of success that children from low-SES backgrounds attain in "learning to talk" negatively influence their "talking to learn". This frequently results in academic failure and premature school exit (Astone and McLanahan 1991; Catts et al. 2002), which perpetuates the cycle of limited post-school earnings and limited life chances (cf. Murnane 2007). As stated by Reilly et al. (2014:430), "it is indisputable that the language skills developed in the first 5 years of life and consolidated throughout children's educational life play a critical role in determining life opportunities". Furthermore, parents whose children attend low-SES schools often perceived their children's teachers as "superior and distant" (Crozier 1999), which discourages positive parent-teacher partnerships (Crozier 1999), and in so doing exacerbates the effect of low SES on educational outcomes.

Early intervention is often recommended to improve the language skills of children from lowSES backgrounds (cf. Knudsen, Heckman, Cameron and Shonkoff 2006) in an attempt to render these children less vulnerable to academic failure and to increase access to better post-school opportunities. Examples of such programmes include Babytalk, HighScope, Sure Start, and the well-known Head Start program. The latter has recently been reported to make almost no difference, when considering the skills of Grade 1 children who had attended the programme compared to the skills of similar children who either stayed at home or attended a different type of preschool programme (cf. U.S. Department of Health and Human Services, Administration for Children and Families, January 2010). However, the call for early intervention, but with appropriate materials and methods, remains (cf. Snowling and Hulme 2012). In response to this call, the first author, together with Ondene van Dulm, developed language intervention material suitable for use with South African child speakers of Afrikaans and English ${ }^{1}$ (cf. Southwood and Van Dulm 2012). This study considers the practice of such early language intervention, which makes use of appropriate material, in one low-SES community.

South African children from low-SES backgrounds generally have alarmingly low literacy levels (Mullis, Martin, Foy and Drucker 2012), which are attributed to poor language skills (Klop and Tuomi 2007), as well as to large classes and overfilled classrooms, a lack of resources, a shortage of trained teachers, and poor pre-literacy skills (Klop and Tuomi 2007:59; cf. also Muijs, Harris, Chapman, Stoll and Russ 2009). These factors exacerbate the language

\footnotetext{
${ }^{1}$ A preliminary isiXhosa version is also available. Final amendments need to be made to this version before it can be published.
} 
and literacy acquisition problems of children with low SES who enter school with poorlydeveloped language skills.

\section{Early intervention for poorly-developed language skills: The current study}

In an attempt to create a supportive environment for language development in young children from low-SES backgrounds, this study aimed to enrich the environment of these children through additional language stimulation. More specifically, the study aimed to establish whether such stimulation, offered in a focused manner over a limited period of time, could yield measurable improvement in the language skills of a group of children in a low-SES area. This study was based on the assumption that children who had not "picked up" language adequately through everyday-occurring interaction - such as listening to, talking to, and interacting with others in their home environment - need more deliberate exposure to certain language structures in order to acquire these structures. For this reason, children in this study were given such deliberate exposure.

The 12 children who participated in this study were 5-years-olds who attended the same preschool in their farming community, located in an isolated valley in the Stellenbosch area. The preschool, run by a non-profit organisation (NPO), aims to provide quality education to children who would otherwise be left vulnerable due to insufficient childcare during the day, when their parents work away from home and their older siblings are at school. The medium of education and administration at the preschool is Afrikaans only, and the vast majority of the children are coloured. ${ }^{2}$ (At the time of the study, there were no white children and only one black child in the school. The latter was the son of Malawian immigrants, spoke English, and was a beginner learner of Afrikaans.) The participating children were in Grade $\mathrm{R}$, the most senior class at the preschool. There were two other classes, one for two- to three-year-olds, and one for three- to four-year-olds. Approximately 60 children attend the preschool, and the staff at the time of the study consisted of three teachers and one administrator, all of whom were coloured. One of the teachers also acts as principal. She had completed matric and obtained a diploma in Early Childhood Development at a regional college. The second teacher's high school education ended after her successful completion of Grade 9. At the time of the study, she was about to enrol for a certificate course in Early Childhood Development at a local training centre. All participating children were taught by the third teacher, who lived in their community and whose biological children had also attended the preschool before entering the only primary school in their valley. Family circumstances prevented her from completing her primary school training (she progressed up to the end of Grade 6), but due to her exceptional child skills and her desire to do meaningful work in her community, the NPO employed her as a teacher in 1999, two years after the preschool was opened. Despite her lack of formal school education, she was granted special entry into the Early Childhood Development course at a regional college, and completed her Level 5 training in the year after the study was conducted. Although the school officially opens at 7:30, some children are present from 7:00 onwards, because the members of their household leave home early. Children can remain at the preschool until 15:30 from Monday to Friday during the Western Cape Education Department school term. The school also runs a holiday club for the children during school holidays, because many

\footnotetext{
2 Although the term "coloured" is widely used in South Africa to refer to persons of "mixed race", we acknowledge that the term is contentious when used as an identifying epithet, amongst others due to its apartheid roots. Although not a preferred term, no suitable alternative has thus far been proposed, and we therefore use the term in this paper, but with due caution and with advance apologies for any offence caused by doing so.
} 
of the parents are not able to take leave for extended periods. All children receive a cooked breakfast, snacks, and a sandwich lunch at the preschool on a daily basis. The monthly school fee was R100 at the time of the study (and still is at the time of writing). Where parents cannot afford this fee, the preschool makes special arrangements. For instance, unemployed parents may offer services to the preschool (such as cooking breakfast) in lieu of paying their children's school fees.

The group that received focused language stimulation (henceforth: language stimulation group) consisted of three boys and two girls, and the group that remained in the classroom while the focused language stimulation took place (henceforth: classroom group) consisted of four boys and three girls. All of them were typically developing according to their community's norms, as reported by their parents and teacher. Participants were recruited in the following manner: Parents of all five-year-olds attending the preschool were informed about the study, and consent forms were provided to all parents via the classroom teacher. All five-year-olds thus had an equal opportunity to participate in the study, but the special criterion for being selected as a member of the language stimulation group was regular school attendance, also during rainy weather in the winter months. (As the majority of the children walk to the preschool, their attendance is dependent on weather conditions and the proximity of their home to the preschool.) The parents of 13 children gave written informed consent for their child's participation. They also filled out a background questionnaire, which asked questions about language, motor and other developmental milestones, and current language skills. Of these 13 children, 6 were identified as regular attenders by their teacher (one later had to be withdrawn from the study due to uncharacteristically poor school attendance during the study period), and the remaining 7 acted as the classroom group. All children gave oral assent to their participation. Parents could withdraw their children from the study at any time, and children could also terminate their own participation.

The period of deliberate language stimulation was preceded and followed by standardised language testing. The instrument used was the Afrikaans version of the Diagnostic Evaluation of Language Variation - Norm Referenced (DELV; Seymour, Roeper and de Villiers 2005; cf. Van Dulm and Southwood 2008 for details on the Afrikaans adaptation, which is in the process of being normed). The DELV was selected because it focuses on language skills and areas of grammar that have been shown to be difficult for children with language impairments, without discriminating against typically-developing children based on their cultural background or language dialect (cf. Seymour and Zurer Pearson 2004). The language testing was performed by the first author and Lauren Onraët, both linguists who are experienced in administering standardised language tests to young children. The language stimulation was provided for one one-hour session per week (18 sessions in total) over a period of six months, excluding school holidays. The language stimulation was provided at the participants' preschool by the second author, a fluent English-Afrikaans bilingual of coloured descent ${ }^{3}$ who was a postgraduate student in the Department of General Linguistics at Stellenbosch University at the time of the study. The study comprised her honours research project. Although she did the language stimulation as part of the fulfilment of degree requirements, she is viewed as a volunteer, because she wilfully chose to be involved in this study rather than in one requiring observation

\footnotetext{
${ }^{3}$ We make mention of race here, because it might be important during the discussion of the outcomes of the language stimulation. The race of the two language test administrators is not deemed important, because their influence on the results of the study is viewed as non-existent; but for the sake of completeness we state that both were white.
} 
or questionnaires only. Indeed, the reason this study appealed to her was that it required volunteerism, and she wanted to have meaningful community interaction during the completion of her honours research project.

The material used during the language stimulation session was the Receptive and Expressive Activities in Language Therapy (REALt; Southwood and Van Dulm 2012). The REALt is a set of language stimulation materials for use with children aged four to nine years who require deliberate exposure to certain language structures in their first or second language, or who exhibit a language delay/disorder. The material was developed based on language development norms reported in the literature. It consists of 361 colour picture items with accompanying text, grouped into easel-backed booklets according to the structures and skills that they target; namely articles, binding, conjunctions, ellipsis, narratives and role-taking, passives, quantifiers, and wh questions. Each of the booklets has several subparts, e.g. comprehension and production, noun vs verb ellipsis, or different types of articles, passive constructions, or wh questions. Each section contains several items, in order to provide multiple opportunities to practice the comprehension or production of a specific structure or skill. The techniques used to elicit responses from the child include focused stimulation, elicited imitation, modelling, expansion, and recasting; and the responses expected from the child include picture selection, picture description, question answering, sentence completion, and story (re)telling. The suggested script for each item faces the adult, while the picture faces the child. All pictures appear in full colour, and the items are based on events in the lives of two neighbouring families. The two families are from different ethnic backgrounds, in a deliberate attempt to offer a wide range of children the possibility of identifying with the characters. The first is a black family living in a comfortable but modest house in the suburbs. The father is a primary school teacher, and the mother runs a baking business from home. They live with their 12-year-old son, 6-yearold twin daughters, and the grandmother. There are two dogs in the household. The skin tone of the second family suggests that they are either white or of "mixed race". The father is a mechanic, and the mother works part-time as a nurse. They have a daughter of 12 years and a son of 4 years. The grandparents also live in the house, and the family has a pet cat. All activities and scenes depicted in the REALt are simple yet interesting, and suitable for a range of socioeconomic and cultural backgrounds. The participants in this study would have been familiar with the living arrangements, occupations, and daily activities of the characters in the material.

Each language stimulation session started with the volunteer interacting with the participating children in their classroom for a short while. Thereafter, the language stimulation group accompanied the volunteer to the preschool's library for an hour. The library is a small room leading from an entrance area (the latter acts as a sick bay, and the administrator's office also leads from this area). The library contains children's books, a television set and DVD player, and a small selection of children's DVDs. (At the time of writing, the library was expanding to include non-children's material as well, in an attempt to make the preschool's library a community resource, as there is no public library in the valley.) The children were allowed "quiet" free play in the library, engaging with puzzles and books, while taking turns to sit individually at a child-sized table with the volunteer to complete at least one target item in each subpart of the stimulus book chosen for the day. (Only one stimulus book was used per session.) In cases where the child did not give the correct response to the item, even after prompting by the volunteer, s/he completed another item in that subpart. Once all the children had individually completed an item for each target structure correctly, the children worked through the rest of 
the items in the stimulus book together. Here, the children were encouraged, and able, to help each other with the responses. During this time, the classroom group received no purposive language stimulation other than that usually received during classroom interaction.

It was expected that the language stimulation group would show improved language skills after the period of six months, and that the classroom group would show no such improvement, other than what could be expected due to natural maturation. The results obtained are summarised below.

The raw scores, domain scaled scores, and percentile ranks obtained on the syntax, pragmatics, and semantics sections of the DELV indicated that deliberate language stimulation seemed to have a positive effect on language development. We report on percentile ranks, which indicate the percentage of cases that are at or below a particular score. A percentile rank of less than 16 (16 being indicative of a score that is higher than that of $15 \%$ of the population and lower than that of $84 \%$ of the population) indicates that the child is "at risk", and that intervention should be considered. We also report on standardised scores. These are converted scores, where 100 is the average of the population, and 86 or higher is within normal limits, irrespective of the age of the child who took the test. The standardised score allows one to compare the relative performance of children of different ages, and it thus also allows one to compare the same child at different times of testing, which is what we did in this study.

For the language stimulation group, the average percentile rank changed from 4.8 prestimulation to 21.8 post-stimulation for syntax; from 26.9 to 25.8 for pragmatics; and from 15.6 to 16.8 for semantics. For the syntax section, all five participants' percentile ranks increased, with three of the ranks being 16 or higher (16+) post-stimulation compared to one prestimulation. For the pragmatics section, one participant's percentile rank increased, and two decreased. Pre-stimulation and post-stimulation, the same three participants had percentile ranks of $16+$ for the pragmatics section. For the semantics section, two participants had percentile ranks of 16+ pre-stimulation, and an additional two (so four of the five participants) post-stimulation. For the test as a whole (all three sections considered together), the average percentile rank was 9.6 pre-stimulation, and 15.4 post-stimulation (the latter thus almost indicative of language skills within normal limits). One child had a percentile rank of 16 prestimulation, and that one was also the only child who had a post-stimulation percentile rank of $16+$. In general, then, the language stimulation group appeared to make gains in the domains of syntax and semantics over the period of six months of language stimulation, but still only one of them had a "not at risk" post-stimulation percentile rank for the language test as a whole. This is confirmed by the standardised scores for the test as a whole: The pre-stimulation scores for this group were 68, 71, 76, 77, and 93; and the post-stimulation scores (presented in the same child-order) were $79,79,80,83$, and 95 . Thus, only one child scored within normal limits (86+), both pre-stimulation and post-stimulation.

To this, one should add the positive reports received from the volunteer and the classroom teacher: Development in the language stimulation group was noticeable over the course of the six months. The children visibly gained familiarity with the content of most of the REALt booklets, especially with wh questions and articles. (Other areas, such as quantifiers and conjunctions, remained problematic, though.) They also became noticeably more confident in their interaction with the volunteer. The teacher found this significant, as the children generally lack self-confidence and become withdrawn when requested to interact verbally in a structured 
setting with outsiders from the community. This group of children also demonstrated increased positive risk-taking during their interaction with the volunteer; in the sense that over time they ventured answers and made guesses about items, which they were not prepared to do at the start of the language stimulation period. The teacher also noticed that the members of the language stimulation group used vocabulary items to which she had not introduced them, and asked more questions than the classroom group. We now turn to the results of the classroom group, before pointing out why the results of the language stimulation group, whilst sounding positive, were still disappointing.

The classroom group showed results on language testing similar to those of the language stimulation group. Their average percentile rank increased from 6.3 pre-stimulation to 11.3 post-stimulation for syntax; from 11.7 to 12.6 for pragmatics; and from 25.0 to 26.7 for semantics. For the syntax section, four of the seven participants' percentile ranks increased and one decreased, with the number of participants with a rank of $16+$ increasing from one prestimulation to four post-stimulation. For the pragmatics section, one participant's percentile rank increased and four participants' decreased, with two of the ranks being 16+ poststimulation compared to one pre-stimulation. Regarding the semantics section, six participants had percentile ranks of 16+ pre-stimulation, but one of these then had a percentile rank of less than 16 post-stimulation, rendering only five $16+$ percentile ranks after the six-month period. For the test as a whole, the average pre-stimulation percentile rank of 9.1 increased to 13.0 poststimulation. One of the seven children had a percentile rank of 16 pre-stimulation, and two (that child and one with a pre-stimulation rank of 9) had a post-stimulation percentile rank of $16+$. Regarding standardised scores for the test as a whole, the children obtained pre-stimulation scores of 73,76, 76, 79, 80, 82, and 88, respectively; and post-stimulation scores of 74, 73, 76, $64,88,79$, and 98 . As was the case for the language stimulation group, only one child had a pre-stimulation composite score that fell within normal limits, and this was the only child in the group of seven who also had such a score post-stimulation. Overall, the classroom group could be said to have made gains in the domains of syntax, pragmatics, and semantics (whereas this could only be said for syntax and semantics in the case of the language stimulation group); but still only two of the group of seven had a "not at risk" percentile rank for the language test as a whole.

When considering the above language test performances, the results were disappointing in two ways. Firstly, both groups made gains, but the scores of the language stimulation group were not noticeably higher than those of the classroom group. A Mann-Whitney U Test indicated no statistically significant difference between the two groups on any of the measures (i.e. each section separately, or all sections combined), with $p>0.05$ in each case. Secondly, also when considering each group separately, the gains that they made from pre-stimulation to poststimulation were not statistically significant; again, $p>0.05$ for each section separately, and for all sections combined. Whereas qualitative gains were reported for the language stimulation group by the volunteer and by their teacher, these gains could not be confirmed quantitatively. These results are even more surprising when one considers that many of the DELV targets are focused on in the REALt.

\section{Reasons for the lack of quantitatively significant gains in language test scores}

In this section, we consider why the only real gains to report after the six-month-long language stimulation programme in the low-SES community described above, namely those reported by 
the volunteer and the teacher, (i) are difficult to measure and (ii) could not be captured by the language assessment instrument.

The first reason could be the language assessment instrument used in this study. Whereas the DELV is purportedly culturally fair ${ }^{4}$ and dialect-neutral ${ }^{5}$, and the reason for the lack of measurable gains can thus not be comfortably ascribed to the test instrument as such, the question arises as to whether standardised testing can yield reliable results with children from low-SES backgrounds. Is formal language testing, regardless of the instrument used, appropriate with children such as those who participated in the current study? There is published evidence that standardised vocabulary testing is biased against children from low-SES backgrounds (cf. e.g. Horton-Ikard and Ellis Weismer 2007), potentially misdiagnosing them as language impaired when they demonstrate typical language-learning abilities. Reports of such bias could however not be traced in the case of the assessment of syntactic, pragmatic, or semantic abilities; and therefore inappropriate assessment practices are probably not to blame for the lack of measurable gains observed in the current study. Generally, researchers call for children to be compared to peers in their speech community rather than to children from vastly different linguistic, cultural, and SES backgrounds. In this study, the children were compared to classmates who lived in their isolated community and to themselves, and thus the issue of unfair comparison does not arise.

The second possible reason for the lack of statistically significant gains could lie with the language stimulation material, or the manner in which it was implemented in the current study. According to the developers, care was taken during the development of the REALt to keep the visual material and depicted scenarios relevant to the lives of children from across the SES range, so inappropriate language stimulation items per se are not apparent causes for the lack of measurable language development in the participating children. The question arises as to whether the children would have shown significant improvement over a longer period of time. In this study, language stimulation took place once a week over a period of six months. Would the study have yielded more significant results had it been conducted over a longer period, offering the participants an increased amount of language stimulation and more individualised attention? If the programme were to be presented over a more extended period, its

\footnotetext{
${ }^{4}$ Whereas we acknowledge that no test can be said to be absolutely culturally fair, not even towards each child member of the culture for which it was designed, about $75 \%$ of the characters in the pictures are of colour (like the participants are). These characters perform simple, everyday activities like eating sandwiches and apples for lunch, walking their dogs, driving cars, and getting dressed; activities with which the participants would have been familiar.

${ }^{5}$ By the term "dialect-neutral", we mean that the test takes into account the syntactic, morphological, lexical, and phonological differences between dialects of Afrikaans (e.g. between so-called "Standard Afrikaans" and Kaaps), and does not discriminate against child speakers who provide a response that would be ungrammatical in Standard Afrikaans, yet grammatical in their dialect of Afrikaans. That said, when one considers Bernstein's (1964) distinction between elaborated and restricted codes, no test can be said to be $100 \%$ sociolect-neutral. According to Bernstein (1964:66-67), children from some working-class homes can be expected to possess only a restricted code (i.e. a code in which it is highly predictable what syntax and vocabulary will be used within a given social context), whereas middle-class children have access to both a restricted and an elaborated code (where the choice of syntax and vocabulary of the latter code is not as predictable). Any test that assesses syntactic knowledge is thus at risk of discriminating against speakers of a sociolect mostly spoken by children from homes with low SES. Bernstein (1964:67) claims that "as a child progresses through a school it becomes critical for him to possess, or at least to be oriented toward, an elaborated code if he is to succeed". With that in mind, it appears reasonable to ascertain whether any child (also those from low-SES backgrounds) possesses the language skills typically associated with an elaborated code.
} 
implementation as part of the classroom activities should be considered, so that the teacher rather than a volunteer can act as language facilitator. A pull-out model such as the one used in the current study, where a group of children are taken out of their classroom for deliberate language stimulation on a weekly basis, could possibly be replaced by one which offers more purposive language stimulation in their immediate environment (at home and during school hours), employing teachers and parents as facilitators.

A third possible reason for the lack of measurable gains could pertain to the characteristics of the volunteer compared to those of the community in which she was working. Several aspects of this possibility are considered below.

\section{Does the problem lie with a mismatch between the volunteer and the community?}

It is worth considering whether there were mismatches between the volunteer and the community that could have influenced the success of the language stimulation programme. The following characteristics are viewed as not likely to have contributed to the lack of statistically significant gains in language skills on the part of the children in the language stimulation group:

(i) The age of the volunteer. She was a postgraduate student of an age similar to that of the preschool's principal (who taught one of the classes at the school). The children would thus have been used to a person of the volunteer's age working at their preschool.

(ii) The gender of the volunteer. She was female, which, at least according to studies done in the United States of America, increases the odds of being a formal volunteer by over 50\% relative to being male (Foster-Bey 2008; cf. also Wymer, Riecken and Yavas 1996). The children at the preschool are used to female adults interacting with them during school hours: All the teachers, the administrator, the parents who perform duties at the school in lieu of paying their children's fees, and the other volunteers that visit the school are also female. Indeed, this volunteer environment is one typically favoured by females over males. Consider in this regard the findings of Wymer's (2010) study: Female volunteers prefer to serve (i) in organisations dedicated to helping the needy, where they can work closely with young children, and/or which emphasise community building; and/or (ii) in volunteer roles which allow them "to develop relational ties with others" (Wymer 2010:14).

(iii) The racial background of the volunteer. As stated above, the volunteer was of coloured descent, and as such she would not have seemed like an outsider to the predominantly coloured community in which the preschool is located.

(iv) The language of the volunteer. She was a bilingual speaker of English and Afrikaans. Although she was familiar with the dialect of Afrikaans spoken in the community, she was not a mother tongue speaker thereof. This might have made the children cautious of interacting with her initially, but, as stated above, she reported that they gained confidence in their interactions with her as time progressed.

One characteristic in which there was a vast mismatch between the volunteer and the preschool community is SES. The children live in a community in which the only primary school is classified as a national quintile 1 school. The national quintile is an instrument used by the South African Department of Basic Education to measure the SES of the community in which a school is situated. This is a pro-poor poverty measure used to determine (i) the amount of 
government funding given to a school and (ii) which schools may charge school fees. A national quintile of 1 is the lowest possible SES, and national quintile 1 schools are fee-free. By contrast, the volunteer comes from a privileged background, when considering the determinants of SES listed by Zappalà and Burrell (2001), namely achievement in education, occupational status, and income and wealth. Although an honours student at the time of the study, the volunteer was not a "typical student", in the sense that she had previously lived and studied abroad and was interrupting her professional career to obtain a postgraduate qualification. As concluded by Zappalà and Burrell (2001:6) upon a review of studies on volunteerism and volunteer commitment, "the findings on socioeconomic status have tended to reinforce the traditional view of volunteering (especially in community services) as a primarily middle-class activity". This holds true for the volunteers who regularly visit the preschool. Like the volunteer in the current study, they are middle-class. Whereas no studies on the impact of a mismatch in SES on the success of volunteerism could be traced, the question arises as to whether such a mismatch is more important in the context of a language stimulation programme than in other contexts.

The reason that a language stimulation programme might be more vulnerable than other programmes to influence by a mismatch in SES pertains to the differences between low- and high-SES communities in childrearing practices and manners of orally interacting with children, which lead to different language outcomes in children. As argued by Tough (1982:6, in reference to the results of her 1977 study), "the children of parents with educational advantage more frequently used language to analyse and reflect on present and past experiences, to reason and justify, to predict and consider alternative possibilities, to talk about events in the future, to project into the lives and feelings of others, and to build up scenes, events and stories in the imagination". This is the type of language use the volunteer would have demonstrated as a child (having grown up in a household where the parents were well educated), and this might have been the type of language use that she would have assumed the children in the language stimulation group to be capable of. There might thus have been a mismatch between the children's employment of language and the volunteer's expectations of their employment of language, which could have led to her not providing enough scaffolding while presenting the items of the language stimulation material to them.

Furthermore, compared to parents in low-SES households, those from higher-SES backgrounds

use a more supportive interactional style in child-directed speech; amongst others, one that contains more questions asked for the purpose of eliciting conversation (cf.; Bee, Van Egeren, Streissguth, Nyman and Leckie 1969; Farran and Haskins 1980; Heath 1983; Hess and Shipman 1965; Hoff-Ginsberg 1991; Schachter 1979). This style has also been called "informative talk" (as opposed to "administrative talk", which mostly entails directives to children; Tizard, Cooperman, Joseph and Tizard 1972); and an "elaborated code", which is linked to democratic values (as opposed to a "restricted code", which is linked to authoritarianism; cf. Bernstein 1971). This results in parents in high-SES households generally talking with their children, whereas parents in low-SES households tend to talk to their children. Furthermore, parents in high-SES households provide greater incidences of affirmative feedback, whereas parents in low-SES households make more frequent use of prohibitions.

(ii) direct a larger quantity of language at their child. Children from low-SES backgrounds tend to have fewer social exchanges, which results in limited exposure 
in their home environment. Specifically, parents in low-SES households do not regularly talk to their child about objects in the immediate environment in an interactive manner (Villanueva 2007:25). Children with low SES also have limited exposure outside of their immediate environment. For example, low-SES households usually cannot afford outings to play parks, speciality shops, museums, and the like. This limits the number of contexts in which children from low-SES backgrounds are spoken to, and thus also the type of vocabulary items to which these children are exposed. Parents from high-SES backgrounds, by contrast, not only tend to use more words and a greater variety thereof, but also tend to use longer sentences (Hart and Risley 1992).

(iii) typically spend more time playing with and talking to their children, which in turn has been shown to positively affect language development in their children (HoffGinsberg 1991:783).

It could thus have been that the volunteer's spoken language interaction with the children was foreign to them, in the sense that her middle-class manner of speaking differed significantly from what they had been exposed to in their homes, and that this left them without a script. According to Nelson (1986), scripts are generalised representations of familiar events or routines, which are organised around a temporal-causal sequence of acts. Children can have scripts for a number of events (such as attending birthday parties or visiting a supermarket) and routines (e.g. meal or bath time, or greeting parents when they return from work). A script entails an ordered sequence of events, required components, and possible variables. For instance, a book-reading script for a pre-schooler may entail knowledge of the order of events (the child fetches the book, hands it to the adult, and sits down next to the adult; the adult reads the title of the book and then turns to the first page, etc.), of the required components (child, adult, book, place to sit) and of the variable aspects (the adult could be the father, mother, older sibling or grandparent; it will not always be the same book that is read in the same place). It could be that the children in this study did not have a script for the language stimulation context created by the volunteer, and that this increased their cognitive load to such an extent that they could not focus on the language targets presented to them (Ellis Weissmer 2000; cf. also Constable 1986; McCormick 1997).

In short, based on the above, we propose that one likely reason for the lack of significant gains in language development despite regular language stimulation by a dedicated volunteer could be that the strategies that the volunteer employed as a middle-class female during conversation with the low-SES-situated children were unfamiliar to them to such an extent that they were unable to fully access the content of what she was saying. Given the lack of traceable studies on mismatches in SES between child-language-related volunteers and the communities in which they render their services, this appears to be a possibility that invites further investigation.

\section{Concluding remarks: Lessons learnt from this study}

This paper considers the apparent failure of early language intervention to achieve its goal, namely to develop the language skills of linguistically under-prepared children to such an extent that they will have a fair chance at participating in classroom discourse. It could be that 18 hours of language stimulation were not sufficient to make a significant difference to the language skills of children from low-SES backgrounds, and that more time would have resulted in more positive results. Alternatively, the pull-out model used during the implementation of 
the language stimulation programme might be unsuitable for a low-SES context in which prolonged language stimulation might be required. An under-researched area is that of SES mismatch between volunteers and the children with whom they are working. It could be that such a mismatch results in the use of discourse strategies by the volunteer that are sufficiently foreign to the children so as to prevent them from benefitting from the content of the language stimulation delivered to them. This possibility requires systematic investigation. The majority of volunteers are from middle-class backgrounds. If they are not the most suitable persons to provide the early language intervention that children from low-SES backgrounds need to improve their language skills, then suitable alternatives need to be considered; for without sufficiently developed language skills, the children might not be able to benefit maximally from the school curriculum, have the prerequisites for developing literacy skills, and participate with ease in classroom discourse.

\section{References}

Astone, N.M. and S.S. McLanahan. 1991. Family structure, parental practices and high school completion. American Sociological Review 6: 309-320.

Bee, H.L., L.F. Van Egeren, A.P. Streissguth, B.A. Nyman and M.A. Leckie. 1969. Social class differences in maternal teaching strategies and speech patterns. Developmental Psychology 1: 726-734.

Bernstein, B. 1964. Elaborated and restricted codes: Their social origins and some consequences. American Anthropologist 66(6:2): 55-69.

Bernstein, B. 1971. Class, codes and control (vol. 1). London: Routledge \& Kegan Paul.

Catts, H., M. Fey, B. Tomblin and X. Zhang. 2002. A longitudinal investigation of reading outcomes in children with language impairments. Journal of Speech, Language, and Hearing Research 45: 1142-1157.

Constable, C. 1986. The application of scripts in the organization of language intervention contexts. In K. Nelson (ed.) Event knowledge: Structure and function in development. Hillsdale, NJ: Lawrence Erlbaum Associates. pp. 205-230.

Crozier, G. 1999. Is it a case of "We know when we're not wanted"? The parents' perspective on parent-teacher roles and relationships. Educational Research 41(3): 315-328.

Cunningham, A.E. and K.E. Stanovich. 1997. Early reading acquisition and its relation to reading experience and ability 10 years later. Developmental Psychology 33: 934-45.

Ellis Weissmer, S. 2000. Intervention for children with developmental language delay. In B.M Bishop and L.B. Leonard (eds.) Speech and language impairments in children: Causes, characteristics, intervention and outcome. Hove: Psychology Press Ltd. pp. 157-176.

Farran, D.C. and R. Haskins. 1980. Reciprocal influence in the social interactions of mothers and three-year-old children from different socioeconomic backgrounds. Child Development 51: 780-791. 
Foster-Bey, J. 2008. Do race, ethnicity, citizenship and socio-economic status determine civicengagement? The Center for Information \& Research on Civic Learning \& Engagement Working Paper 62.

Hart, B. and T.R. Risley. 1992. American parenting of language-learning children: Persisting differences in family-child interactions observed in natural home environments. Developmental Psychology 28(6): 1096-1105.

Hart, B. and T.R. Risley. 1995. Meaningful differences in the everyday experience of young American children. Baltimore: Paul H. Brookes.

Heath, S.B. 1983. Ways with words: Language, life, and work in communities and classrooms. Cambridge: Cambridge University Press.

Hess, R.D. and V.C. Shipman. 1965. Early experience and the socialization of cognitive modes in children. Child Development 36: 869-886.

Hoff-Ginsberg, E. 1991. Mother-child conversation in different social classes and communicative settings. Child Development 62(4): 782-796.

Horton-Ikard, R. and S. Ellis Weismer. 2007. A preliminary examination of vocabulary and word learning in African American toddlers from middle and low socioeconomic status homes. American Journal of Speech-Language Pathology 16: 381-392.

Klop, D. and S.K. Tuomi. 2007. The persistence of language disorders in a group of disadvantaged Grade 3 learners. The South African Journal of Communication Disorders 54: 59-66.

Knudsen, E.I., J.J. Heckman, L.J. Cameron and J.P. Shonkoff. 2006. Economic, neurobiological, and behavioral perspectives on building America's future workforce. Proceedings of the National Academy of Sciences 103: 10155-10162.

McCormick, L. 1997. Language intervention and support. In L. McCormick, D. Frome Loeb and R. Stiefelbusch (eds.) Supporting children with communication difficulties in inclusive settings: School-based language intervention. Needham Heights, MA: Allyn \& Bacon. pp. 257306.

Muijs, D., A. Harris, C. Chapman, L. Stoll and J. Russ. 2009. Improving schools in socioeconomically disadvantaged areas - A review of research evidence. School Effectiveness and School Improvement 15: 149-175.

Mullis, I.V.S., M.O. Martin, P. Foy, and K.T. Drucker. 2012. PIRLS 2011 International Results in Reading. Chestnut Hill, MA: TIMSS \& PIRLS International Study Center, Boston College.

Murnane, R.J. 2007. Improving the education of children living in poverty. The Future of Children 17(2): 161-182. 
Nelson, K. 1986. Event knowledge: Structure and function in development. Hillsdale, NJ: Lawrence Erlbaum Associates.

Raizada, R.D.S., T.L. Richards, A. Meltzoff and P.K. Kuhl. 2008. Socioeconomic status predicts hemispheric specialisation of the left inferior frontal gyrus in young children. NeuroImage 40: 1392-1401.

Reilly, S., B. Tomblin, J. Law, C. McKean, F.K. Mensah, A. Morgan, S. Goldfeld, J.M. Nicholson and M. Wake. 2014. Specific language impairment: a convenient label for whom? International Journal of Language and Communication Disorders 49: 416-434.

Roy, P., S. Chiat and B. Dodd. 2014. Language and socioeconomic disadvantage: From research to practice. London, UK: City University London.

Scarborough, H.S. 2001. Connecting early language and literacy to later reading (dis)abilities: Evidence, theory and practice. In S.B. Neuman and D.K. Dickinson (eds.) Handbook of early literacy research (vol. 1). New York: Guilford Press. pp. 97-110.

Schachter, F.F. 1979. Everyday mother talk to toddlers: Early intervention. New York: Academic Press.

Seymour, H.N., T. Roeper and J.G. de Villiers. 2005. Diagnostic Evaluation of Language Variation - Norm-Referenced. San Antonio, TX: Pearson.

Seymour, H.N. and B. Zurer Pearson. 2004. Steps in designing and implementing an innovative assessment instrument. Seminars in Speech and Language 25(1): 27-31.

Snow, C.E., M.S. Burns and P. Griffin. 1998. Preventing reading difficulties in young children. Washington, DC: National Academy Press.

Snowling, M.J. and C. Hulme. 2012. Interventions for children's language and literacy difficulties. International Journal of Language \& Communication Disorders 47(1): 27-34.

Southwood, F. and O. Van Dulm. 2012. The Receptive and Expressive Activities for Language Therapy. Johannesburg: JvR Psychometrics.

Tizard, B., O. Cooperman, A. Joseph and J. Tizard. 1972. Environmental effects on language development: A study of young children in long-stay residential nurseries. Child Development 43: 337-358.

Tough, J. 1977. The development of meaning. London: Allen and Unwin.

Tough, J. 1982. Language, poverty and disadvantage in school. In L. Feagans and D.C. Farran (eds.) The language of children reared in poverty. New York and London: Academic Press. pp. 3-18.

U.S. Department of Health and Human Services, Administration for Children and Families. January 2010. Head Start impact study. Final report. Washington, DC. 
Van Dulm, O. and F. Southwood. 2008. Towards a dialect-neutral Afrikaans-medium child language assessment instrument: Test item development. Language Matters 39: 300-315.

Van Rooyen, D. and H. Jordaan. 2009. An aspect of language for academic purposes in secondary education: Complex sentence comprehension by learners in an integrated Gauteng school. South African Journal of Education 29: 271-287.

Vernon-Feagans, L. 1996. Children's talk in communities and classrooms. Cambridge, MA: Blackwell Publishers.

Vernon-Feagans, L., C. Scheffner Hammer, A. Miccio and E. Manlove. 2002. Early language and literacy skills in low-income African-American and Hispanic children. In S. Neuman and D. Dickinson (eds.) Handbook of early literacy research. New York: Guilford Press. pp. 192210.

Villanueva, J.C. 2007. Parenting practices and language development in low SES Spanishspeaking families. SJSU Scholar Works 1: 20-27.

Westby, C. 1994. Communication refinement in school age and adolescence. In O. Haynes and B. Shulman (eds.) Communication development: Foundations, processes and clinical applications. Englewood Cliffs, NJ: Prentice-Hall. pp. 311-360.

Wymer, W. 2010. The implications of sex differences on volunteer preferences. International Society for Third-Sector Research and The Johns Hopkins University 2010.

Wymer, W., G. Riecken and U. Yavas. 1996. Determinants of volunteerism: A crossdisciplinary review and research agenda. Journal of Nonprofit \& Public Sector Marketing 4: 326.

Zappalà, G. and T. Burrell. 2001. Why are some volunteers more committed than others? A socio-psychological approach to volunteer commitment in community services. Research \& Social Policy Team of The Smith Family Working Paper 5. 